\title{
4 The Higher Education Trajectories of Taiwanese Women in STEM
}

\author{
A Longitudinal Analysis
}

\author{
Yuan Chih Fu, Amelio Salvador Quetzal and \\ Yuehluen $\mathrm{Hu}$
}

The participation and status of women, compared with men, in science, technology, engineering and mathematics (STEM) has been of utmost global concern (van Staden et al. 2019; Penner, 2015). This concern is derived from two sets of issues that countries deal with: the provision of human resources for the STEM workforce and social equity in access to and rewards for professional participation in these fields (Fox, 2010). Although women now surpass men in college participation (DiPrete \& Buchmann, 2013), there are still concerns about an undersupply of STEM graduates and a shortfall of women in the pursuit of STEM majors and careers (U.S. Department of Commerce and National Economic Council, 2012). Though the numbers may have improved over the decades, it might still be a long way to go before women are on a par with men in STEM fields (Blickenstaff, 2005).

The expansion of tertiary education has become a global norm of modernization over the past decades, particularly because there has been an increasing demand for it (Marginson, 2016). At the policy level, expanding tertiary education might translate into creating increased accessibility for all, especially for women. Notwithstanding that, it remains unclear whether creating access through expansion really translates into a more equal world (Marginson, 2016; Baker, 2011). While there are many facets to explore within the issue of expansion and accessibility of tertiary education, this study focuses on women in STEM and how they have been impacted by the expansion of tertiary education in Taiwan.

The capacity of Taiwan's tertiary education system has expanded rapidly since the 1990s. The number of four-year universities increased from 50 in 1992 to 140 in 2018. Similarly, the number of students attending universities increased from 0.27 million to 0.93 million (Ministry of Education, 2019a). At this stage, Taiwan now has what Trow (1973) calls a universal education system given that its gross enrollment ratio (GER) in Higher Education Institutions (HEIs) has exceeded $50 \%$ of the tertiary education schooling age cohort. Taiwan has also grown as an important producer of STEM research in the region (Fu, 2017). However, what remains to be understood is whether

DOI: $10.4324 / 9781003053217-9$ 
the expansion of Taiwan's tertiary education provided more access and opportunities for women in STEM. Along those lines, further statistics show that the GER of the relevant age group was $14.50 \%$ among women in 1981, which increased to $89.53 \%$ in 2018 , much higher than the GER (80.24\%) among men in the same year (Ministry of Education, 2019b).

Despite the existence of several studies which have analyzed the importance of tertiary education expansion across countries (Breen, 2010; Shavit, et al., 2007; Hannum \& Buchmann, 2005), some key questions are still unclear in the case of Taiwan. First, has the expansion of Taiwan's tertiary education system provided more access and opportunities for women in STEM? If it has, how did it happen? Second, does the growth of women's participation in the STEM educational pipeline influence their participation in the labor market? Do they experience discrimination which prevents them from pursuing STEM professions? With 38 years of data in education and the labor market, this study investigates how the expansion of the tertiary education system reshaped the educational opportunity of women in STEM and subsequently the structure in the labor market of STEM professionals in Taiwan.

\section{Historical Overview of Educational Reform in Taiwan}

Since the 1990s, the Taiwanese government initiated a series of educational reforms mainly designed to facilitate educational equality. The policy, driven by this purpose of educational equality, directly impacted upper secondary and tertiary schools. Before the policy action, at the upper secondary level, vocational-oriented senior high schools were seen as secondary to the academic-oriented senior high schools. Moreover, the academic-oriented programs offered in the senior high schools would lead students to university enrollment, whereas the vocational-oriented programs would only lead them to enroll in junior college. The intensive pressure derived from striving to gain admission into senior high schools was often mentioned as the reason for lower secondary high schools focusing solely on preparing their students for admission exams.

Thus, the first policy action was educational reform at the upper secondary school. Taiwan follows the dual-track system which was set up during the Japanese colonial period. Junior high school graduates may choose between an academic-oriented senior high school or a vocational-oriented one. Since 1992, the Ministry of Education (hereafter, MOE) began to increase the number of upper secondary schools from 177 to 513 . With this policy change, some vocational-oriented senior high schools began to replace their vocational-oriented programs with academic-oriented ones.

The second policy action was the transformation of junior colleges into universities. The expansion of tertiary education in Taiwan was mainly driven by increasing the number of four-year technological universities by upgrading two-year junior colleges. From 1996 to 2007, among 70 two-year junior colleges, 53 were upgraded to four-year technological universities or institutes of 
technology. The impact of such expansion was dramatic in two ways. First, the extension of an additional two years transformed vocational education into professional education, offering an opportunity for students to compete for professional positions in the labor market. Second, the increasing capacity of tertiary education accommodated more school-age youth and offered them more opportunities to explore their career options. ${ }^{1}$

\section{Human Capital Theory and Educational and Occupational Choices}

Despite the existence of a copious amount of studies and decades of statistics which underscore the underrepresentation of women in STEM fields, particularly in the United States (Bentley \& Adamson, 2003), little is known about the opportunities provided to and occupational choices of women in STEM after the expansion of Taiwan's education system. To better understand such phenomenon, this study is guided partly by the principles of the human capital theory (HCT) and self-selection as observed from literature mostly derived from the United States.

Under the lens of HCT, individuals make educational and occupational decisions based upon a calculation of associated costs and benefits $(\mathrm{Xu}, 2015)$, which can potentially increase their human capital and affect their participation in the labor market. Within this context, women tend to perceive STEM careers as being thing-oriented (compared to personal contact-oriented), resulting in less time for oneself, and being antithetical to communal goals (Kang et al. 2018). Women continuously demonstrate less interest in STEM occupations (Ceci \& Williams, 2010; Diekman et al., 2010) because they prefer more family-friendly, personal contact-oriented occupations than men (Konrad et al. 2000). Put differently, HCT attributes the underrepresentation of women in STEM partly to differences in gender role socialization and the selectivity bias derived from self-selection (Fox, 2010). Such preconditions on STEM fields can in turn determine women's choice of occupation and employment $(\mathrm{Xu}, 2015)$.

Thus, from the HCT perspective, the underrepresentation of women is a result of women choosing not to pursue STEM careers. Despite the notion that tertiary education expansion is expected to raise the human capital of women entering STEM fields, it appears that they perceive entering into such grounds as less beneficial to them. In fact, due to gender-related career expectations and the traditional division of household labor, women have different preferences than men in choosing college majors and subsequent occupational paths (Frome et al. 2006). Women's low participation in STEM, therefore, becomes a social problem as women tend to choose female-dominated occupations which have lower income levels and less advancement opportunities than traditionally male-dominated occupations (Okamoto \& England, 1999).

In addition to the self-selection driven by social expectation along gender lines, the education system itself plays a crucial role in worsening such 
segregation. For example, in the classroom, teachers tend to underestimate the academic ability of women in STEM, thereby giving women students less attention and encouragement (Riegle-Crumb et al., 2011). This barrier creates the notion that STEM programs are male-dominated (Lee, 2008), which is exacerbated by the stereotyping beliefs of teachers, parents, and peers (Saucerman \& Vasquez, 2014). The effect of gender stereotyping is that women get the idea they need to avoid studying in an environment where they are "not treated equally or fairly," a concept that Seaton $(2011$, p. 6) described as a "chilly climate." This may eventually lead to a pattern of women opting out of pursuing STEM which is driven by the education system itself.

Lastly, it has been documented that having women as role models increases young women's attitudes and self-concepts on mathematics and science subjects, thereby expanding their ability to consider STEM fields as major and career options (Corbett \& Hill, 2015; Cheryan et al., 2011). However, in school and society, girls lack role models such as successful women STEM professionals (Lee et al. 2015). Such a situation further exacerbates the idea of a chilly climate that women students face in the STEM fields. Additionally, studies have documented that parents influence their daughters' tertiary educational decisions to choose non-STEM fields (Astin \& Sax, 1996; Shapiro \& Sax, 2011). In sum, women may choose to study in the non-STEM fields because the rewards are different between genders (Mann \& DiPrete, 2013).

\section{Schools and The Leaky Pipeline}

Although there is abundant knowledge about how women are discriminated against within the "STEM pathway" (Wang \& Degol, 2013, p. 305), we know very little about how the structure of the schooling system could worsen or improve such gender inequality. Probably one of the most cited metaphors that describes how schools affect or impact the participation of women in STEM is the "leaky pipeline."

According to the leaky pipeline metaphor, as students move through the STEM pathway, a leaky pipeline leads to decreased representation of women in STEM resulting from a steady attrition of women in the education system and the professional hierarchy (Blickenstaff, 2005). This steady attrition of women might be attributed to system related factors. For instance, preparation in science and mathematics during the middle and high school years is often cited as an important influence on women's decisions to enter or exit STEM majors in college (Seymour \& Hewitt, 1997). Similarly, studies have shown that the disadvantages women face could potentially appear much earlier than expected and exacerbate attrition as they move through the STEM pathway. By studying Germany's population, Kinzie (2007) found that women's pathways into or out of STEM fields are already formed in eighth grade. At this age, it appears that feelings of belonging and integration appear to be essential to be able to fit in and persist in STEM disciplines. 
Furthermore, women's differential STEM course-taking and preparation in their pre-college years appear to be influenced by different factors, which can limit their access to STEM careers later on. Women who do not take the math and science courses needed to access a STEM career are often unable to stay in the science and mathematics pipeline (Huang \& Brainard, 2001) and are eventually "leaked out." Empirical evidence also exists for the assumption that STEM courses are primarily "masculine" and are consequently less appealing to female students (Wang \& Degol, 2013; Blickenstaff, 2005), thereby making them persist less than men within the STEM pathway. Some studies also show that the instructional techniques adopted by STEM teachers favor men over women because they use fewer cooperative approaches, which are more appealing to women (Kelly, 2016; Wang \& Degol, 2013). The longstanding gender stereotype inherent in the STEM field might also influence teachers and advisors towards a biased assumption that women do not belong in the STEM field (van den Hurk et al., 2019). Such prejudiced notions might create a negative social atmosphere for girls pursuing STEM programs, thereby adversely influencing their sense of belonging and competence (Eddy \& Brownell, 2016; Kelly, 2016; Wang \& Degol, 2013). Thus, although STEM disciplines are ostensibly gender-blind, structural barriers appear to have emerged which allow women to be "leaked out" because they are treated as "strangers" in STEM fields (Sonnert et al., 2007; Smith, 2011).

Aside from looking at women's differential STEM course-taking patterns in their pre-college years, early streamlining in a schooling system might exacerbate such segregation (Jacobs, 1989) to a point of no return. In Taiwan, for instance, where the schooling system adopts early streamlining, students make their first educational decision by the ninth grade. At the upper secondary level, students are placed in the academic-oriented or vocational-oriented tracks. Unique to Taiwan, students in the vocational-oriented tracks can go into STEM or nonSTEM programs. The vocational non-STEM program is particularly designed for those students who commit to non-STEM careers. True to its mission, the course structure in the vocational non-STEM program leaves almost no space for STEM courses, which means that students' exploration of STEM courses would be halted by the ninth grade; these students are subsequently excluded from the STEM pathway. The junior college, which only offers two-year associate degree programs, cannot fully prepare students for STEM professions within that time. Thus, under such circumstances, and given the preconditions previously discussed, women are most likely vulnerable in the "leaky pipeline," thereby further widening the gap between men and women within STEM fields.

\section{The Effects of Tertiary Education Expansion on Women in STEM}

It appears that expanded higher education systems have afforded more opportunities for higher education participation across the globe. A result of such expansion is a significant impact on patterns of gender parity and the 
participation of men and women in selected fields (Chang \& ChangTzeng, 2018). For instance, by studying three distinct cohorts representing the high school graduating classes of 1972, 1982, and 1992 in the United States, Flashman (2013) indicates that the expansion of higher education, particularly from two-year to four-year colleges, increased opportunities for enrollment, and women disproportionately took advantages of these opportunities. Regarding the participation of women in STEM fields, Xie and Shauman (2003), who followed a life course perspective (from middle school through career years) and used rigorous multivariate methods on data from 17 large national datasets in the United States, found that gender differentiation has declined little compared to decades ago in a less expanded education system. More recently, Severiens and ten Dam's (2012) study, which used Dutch census data on higher education from 1995 to 2006, indicated that women, on average, outnumber men and are more successful in the bachelor years of higher education.

Thus, it remains obvious that an expanded education system provides differential opportunities for participation. In Taiwan, in particular, the number of students participating in higher education has increased substantially since its expansion in the early 1980s. According to the '2015 Education Statistical Indicators,' the tertiary education GER reached $83.88 \%$ in 2013, higher than their counterparts in most Asian countries (Chang, 2018). Furthermore, as it relates to women's participation in higher education, there are more women students than men students who enrolled in higher education institutions since 1995 (Ministry of Education, 2019b). This trend shows that in Taiwan the expansion of higher education has favored women students more than men. However, what is not clear is whether it transformed the traditional gender stereotype inherent in STEM educational fields and occupational choice.

\section{Methodology}

\section{Data Description}

We use 38 years (1979 through 2017) of national survey data, including the 'manpower utilization quasi-longitudinal data' managed by Academic Sinica (2018), a leading national research institute in Taiwan. We calculate the participation rate in STEM professions and the educational matching rate of men and women at the ages of 25-35. Using administrative records managed by the MOE, we also calculate the share of graduates by gender and educational track over the past 30 years at the upper secondary and tertiary educational levels. The compiled longitudinal data reflects the changing structure in the labor market fueled by the expansion of higher education. The compiled data contains three dimensions. The first one is the share of graduates at the upper secondary level from 1992 to 2017 by three different tracks: academic, vocational education in STEM, and non-STEM. The second one is the share of graduates at the tertiary education level from 1992 to 2017 by four different 
tracks: associate degree in STEM, associate degree in non-STEM, bachelor's degree in STEM, and bachelor's degree in non-STEM. The last one is occupational participation from 1979 to 2017 by gender and professional type.

\section{Analytic Strategy}

To ensure consistency in definition, this study differentiates the STEM and non-STEM disciplines and professional occupations by referring to Beede et al. (2011)'s classification. In order to measure the historical change, we use the percentage share of men and women in the STEM educational track (i.e., upper secondary and tertiary educational levels) and professional occupations accounting for their own gender population. This approach can obviate the confusion inherent in using total amount or percentage changes, particularly in historical investigations (Geiger \& Feller, 1995). Additionally, since the 'manpower utilization quasi-longitudinal data' follow the survey design, data were weighted. We then use frequency weights to estimate the descriptive statistics (Academia Sinica, 2018). Since the interest of this study is to capture the historical trend of women's participation rate in STEM, it uses the median spline method to smoothen the line connecting each annual value point.

\section{Findings}

\section{Shifting Composition of Educational Pipeline}

Figure 4.1 indicates the shifting composition of the educational pipeline of the two gender groups at the upper secondary and tertiary educational levels. Figure 4.1A and 4.1B indicate the changing composition of men and women upper secondary school graduates among three different tracks. The solid line indicates the share of graduates in the academic track, the dashed line indicates the share of graduates in the vocational STEM track, and the dotted line indicates the share of graduates in the vocational non-STEM track. Figure 4.1C and 4.1D indicate the changing composition of male and female postsecondary graduates. The solid line indicates the share of graduates in STEM at bachelor degree level and the dashed line indicates the share of graduates in STEM at associate degree level.

The educational reform during the late 1990s brought direct but heterogeneous impacts on the two gender groups in terms of accessibility in STEM. First, the educational reform at the upper secondary level was to downsize the scale of vocational track programs and to expand the scale of the academic track. Since 1990s, the ratio of total graduates between academic and vocational tracks changed from 2.5:7.5 to 4.8:5.1. About $22.5 \%$ of youth who used to be placed in the vocational track program changed to academic programs at the upper secondary high school level.

Such change also reshaped the educational opportunity of the two gender groups. In 1992, the men in the academic track accounted for $29.3 \%$ of the 

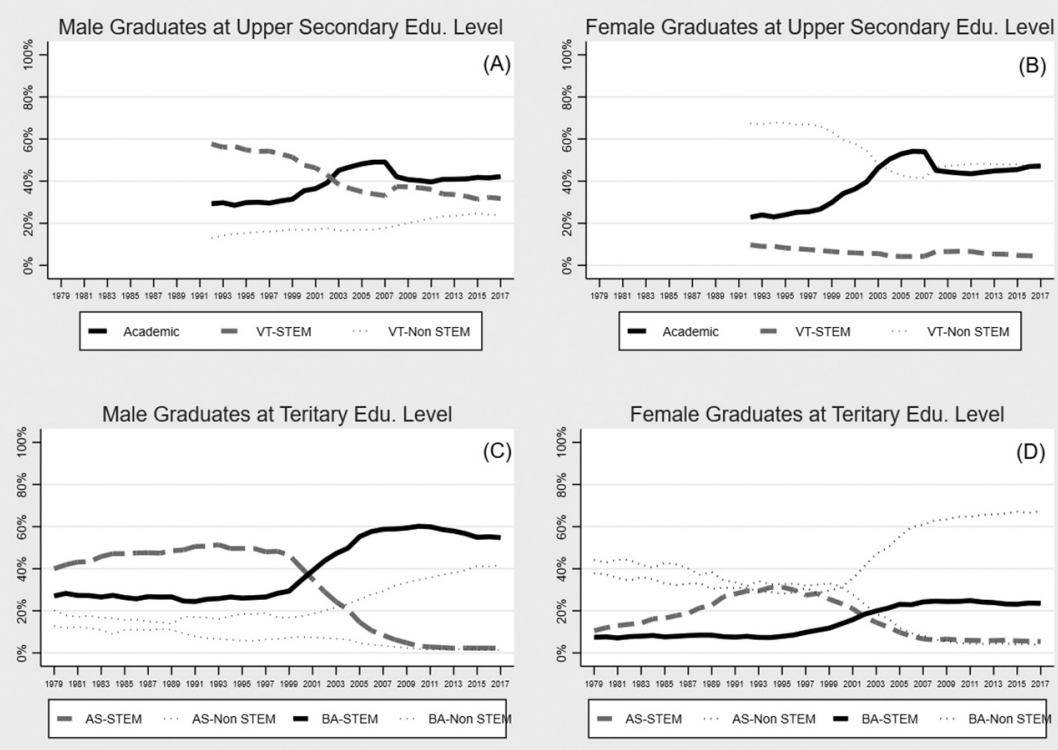

Figure 4.1 A-D. The share of male and female graduates by educational track, 19792017.

total enrolled men students, while women students in the academic track accounted for $22.9 \%$ of all women. By 2017 , the percentage in the men group increased to $42.2 \%$ while the women group increased to $47.2 \%$. The additional growth in the academic track on the two gender groups came from different resources. As for the men group, during the same period, the vocational track STEM programs decreased from $57.7 \%$ to $31.8 \%$, yielding $25.9 \%$ to the rest of the tracks. The share of men students in the academic track program increased by $12.9 \%$. Simultaneously, the vocational track nonSTEM program increased by $10.8 \%$, from $13.1 \%$ in 1992 to $23.9 \%$ in 2017 . Overall, more men students delayed their tracking decision. However, among those early-decided men students, the portion of men students choosing not to go on the STEM track increased as well.

Different from the decrease of the men students in the vocational track STEM programs, the significant decline among women appears in the vocational track non-STEM programs. In 1992, 67.4\% of women students were in vocational track non-STEM programs. By 2017, only $46.6 \%$ of women students were left. The vocational track STEM programs also experienced a modest decline, decreasing from $9.7 \%$ to $4.3 \%$ during the same period. The vocational track lost women students to the academic track programs, which experienced $24.3 \%$ growth. Compared to the older generation, the younger women generation had more opportunity to explore their interest in STEM fields via the academic track. On the other hand, there were still $46.6 \%$ of 
women students who chose a non-STEM track through the vocational track; but only $23.9 \%$ of men students made the same choice.

We then focus our investigation on the impact of tertiary education expansion on the two gender groups. Due to the notion that tertiary education expansion is mainly driven by the transformation of junior colleges, the direct impact based on this change is the extended length of education and the type of degree awarded. Particularly for those students who used to finish their studies at junior college, four-year tertiary education meant the transformation of vocational education into professional education. This change offered them better opportunities to obtain a STEM professional position.

As observed at the upper secondary school level, tertiary education expansion brought heterogeneous effects to the two gender groups. Referring to men, in 1979, $40.0 \%$ of men who enrolled in tertiary education had an associate degree in STEM fields. In the same year, only $27.1 \%$ of the men completed four-year tertiary education and graduated with a bachelor's degree in STEM fields. Since 2000, affected by the increasing capacity at universities, the percentage of men students studying in STEM fields started growing. Within ten years, by 2010, the percentage of fouryear STEM degrees reached a peak of $60.2 \%$. At the same time, only $3.3 \%$ of men students graduated with an associate degree in STEM fields.

Soon after the peak in 2010, the percentage of men students choosing STEM fields at the university level started to decline. By 2017, the number decreased to $54.8 \%$. The percentage of men students choosing non-STEM programs at universities increased from $34.6 \%$ in 2010 to $41.7 \%$ in 2017 . The reduction of men students in STEM fields implies that men students no longer enrolled overwhelmingly in STEM fields. To a certain degree, young men were less constrained by the gender stereotype in choosing their major fields.

Tertiary education expansion also changed the landscape of educational choice for women students. In 1979, only 7.5\% of women who enrolled at tertiary education earned bachelor's degrees in STEM fields. Even for associate's degrees, only $10.5 \%$ of women students graduated in STEM fields. The percentage of women students graduating with an associate degree in STEM increased to $31.3 \%$ in 1995 . At that time, only $7.9 \%$ of women students at universities were studying in STEM programs.

Soon after 1995, when the majority of the junior colleges started to transform into universities, women who would have graduated with an associate's degree in STEM fields now graduated with a bachelor's degree. From 1995 to 2007, the percentage of women who graduated with a bachelor's degree gradually increased and reached a saturation point $(24.2 \%)$ in 2007 followed by a ten-year flat curve until 2017. On the other hand, from 1995 to 2007, the percentage of women who graduated with associate's degrees in STEM continually declined. By 2017, only $5.4 \%$ of women students were left in two-year STEM programs. As observed among men, the growth of women in STEM bachelor programs came from the loss in associate degree programs. However, compared to 2005, by 2017 there were $10.2 \%$ less women students enrolled in STEM programs either at a junior college or a university. 


\section{Yuan Chih Fu et al.}

From the upper secondary to tertiary level, there are different degrees on the leaky pipeline among the two gender groups. Upon their graduation from upper secondary school, by 2017 , there were $42.2 \%$ and $31.8 \%$ of men students in the academic and vocational track STEM programs, respectively. By 2017, 54.8\% of men students earned bachelor degrees in STEM fields. Although there were $47.2 \%$ and $4.3 \%$ of women students in the academic and vocational track STEM program, respectively, only $23.6 \%$ of them earned bachelor degrees in STEM fields. Although our statistics cannot show their preferences for academic tracks at the upper secondary level, this suggests that among 100 men and women senior high school graduates who chose academic tracks in STEM programs, 74 men and 45 women students would eventually choose STEM fields and graduate.

Based on the historical overview, two important findings appear. First, the expansion of tertiary education did enhance women's opportunities to complete four-year tertiary education for STEM professions. However, during the period of expansion, the percentage of men and women in STEM decreased at both the junior college and university levels. Second, although the reform at the upper secondary level postponed women's educational choice and provided them more opportunities to explore STEM courses, women students still appeared to face severe problems within the leaky pipeline between the upper secondary and tertiary levels.

\section{Convergence of Participation in STEM Professional Positions}

The increasing number of women with professional education in STEM fields changed the structure of human resources in the labor market. Table 4.1 reveals the participation rate of the population at ages 25-35 in STEM professions by gender while Figure 4.2 visualizes the historical trend.

Table 4.1 The Participation Rate of 25-35-year-olds in STEM Professions

\begin{tabular}{lrrrrrrrrr}
\hline & Weighted sampling size & & \multicolumn{3}{c}{ STEM professionals (\%) } & \multicolumn{4}{c}{$\begin{array}{l}\text { STEM education and occupa- } \\
\text { tion match }(\%)\end{array}$} \\
\hline Year & Men & Women & Total & Men & Women & total & Men & Women & Total \\
\hline 1979 & 487,124 & 458,485 & 945,609 & 1.98 & 0.12 & 1.08 & 46.42 & 25.18 & 44.82 \\
1981 & 671,656 & 637,759 & $1,309,415$ & 1.92 & 0.30 & 1.13 & 35.65 & 50.26 & 36.78 \\
1986 & 847,265 & 752,384 & $1,599,649$ & 1.76 & 0.47 & 1.16 & 31.65 & 53.58 & 34.00 \\
1991 & 893,062 & 825,421 & $1,718,483$ & 2.43 & 0.95 & 1.72 & 40.36 & 60.05 & 43.81 \\
1996 & 909,554 & 838,710 & $1,748,264$ & 3.50 & 1.09 & 2.35 & 43.77 & 57.12 & 46.24 \\
2001 & 918,671 & 855,287 & $1,773,958$ & 6.11 & 1.77 & 4.01 & 52.94 & 52.09 & 52.78 \\
2006 & 968,146 & 918,688 & $1,886,834$ & 11.43 & 4.58 & 8.09 & 56.11 & 60.63 & 57.19 \\
2011 & $1,007,265$ & 959,640 & $1,966,905$ & 14.71 & 6.42 & 10.66 & 49.22 & 56.47 & 51.08 \\
2016 & 932,326 & 894,055 & $1,826,381$ & 14.73 & 10.40 & 12.61 & 44.94 & 57.90 & 48.77 \\
2017 & 834,190 & 838,348 & $1,672,538$ & 15.74 & 10.01 & 12.87 & 41.74 & 53.34 & 45.14 \\
\hline
\end{tabular}


Shown in Figure 4.2A, over the past 38 years, both gender groups experienced three different stages. In the first stage, from 1979 to 1990, the share of STEM professional occupations by gender basically reflects the gender composition within tertiary education. During this period, men dominated STEM professional occupations as they dominated STEM programs in universities. On average, the ratio between the two gender groups was 5:1. Inequality in the education pipeline followed by inequality in the labor market is very apparent.

Entering the second stage, from 1991 to 2001, Taiwan's economy gradually shifted towards high-tech industries. The growth of high-tech industries offered more professional positions. The percentage of 25-35-year-olds who had STEM professional occupations increased from $1.72 \%$ to $4.01 \%$, almost 2.5 times. During this period, men took the lion's share of this growth. In 1991, only $2.43 \%$ of men took a STEM professional position in the labor market. By 2001, this number increased to $6.11 \%$, almost 2.5 times more. In contrast, the growth of women was under the national average. In 1991, $0.95 \%$ of women took STEM professional positions. By 2001, this number increased about 1.8 times to $1.77 \%$. The participation rate of women in STEM professions increased as a reflection of the increasing share of women graduates with bachelor's degrees in STEM since 1995. As seen in Figure $4.1 \mathrm{D}$, the trend took off soon after 1995. By 2001, about $17 \%$ of women had

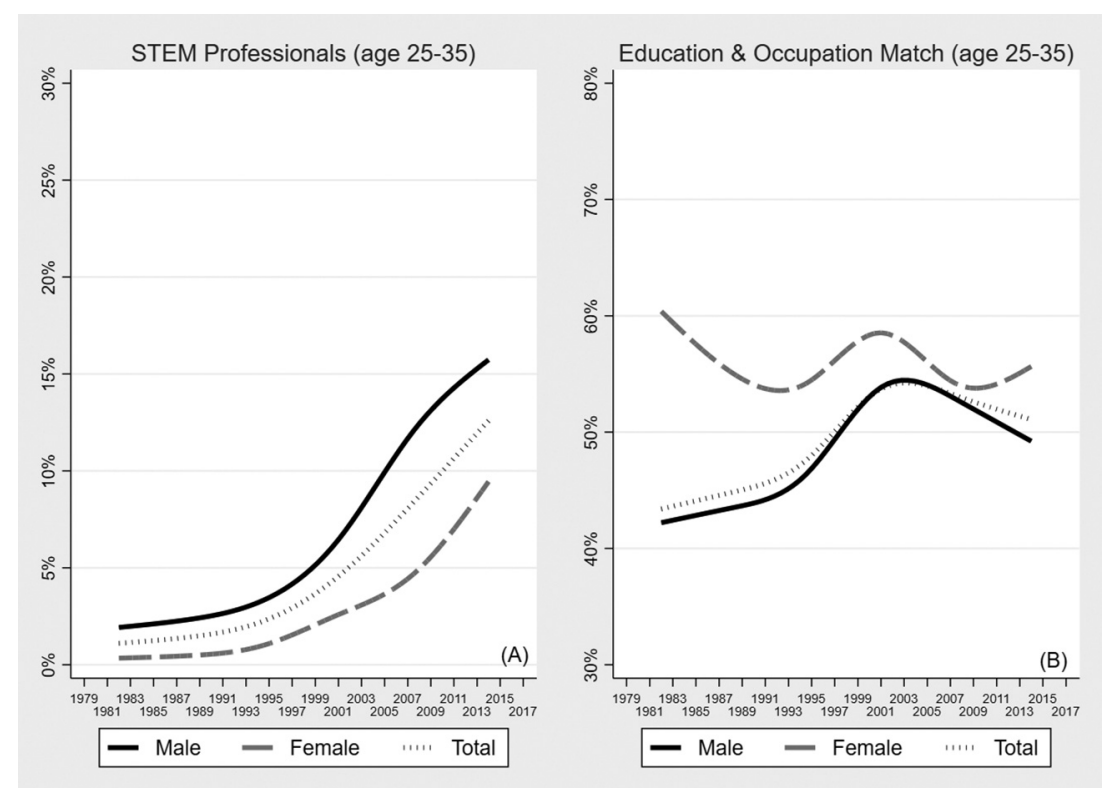

Figure 4.2 The impact of education expansion on occupational choice, 1979-2017. Note: Median smoothing applied. 
a bachelor's degree in STEM. This growth also reflected the rise in the labor market, although mildly. Overall, the segregation by gender in the STEM professional job market was improving. The ratio between the two gender groups shrunk from 5:1 to $3: 1$.

In the third stage, from 2001 to 2017, the convergence of participation in STEM professions between the two gender groups became obvious. As the impact of tertiary education expansion became stable (after 2001), the population trend accounting for the number of graduates by gender cohort in STEM fields also plateaued (see Figure 4.1). However, the demand for STEM professional positions in the labor market grew continually. The percentage of the youth generation who had STEM professional occupations increased from $4.01 \%$ to $12.87 \%$, almost 3.2 times more. This exponential growth reflected the urgent demands of high-tech professionals in the knowledge economy.

It is noteworthy that when men's participation rate is approaching its saturation point, shown as the S-shaped curve, women's participation rate keeps its growth momentum. In 2001, 6.11\% of males had a STEM professional position in the labor market. By 2017, this number increased to $15.74 \%$, almost 2.5 times more. Dramatically, women's growth is well above the national average. In 2001, 1.77\% of women had a STEM professional position. By 2017, this number increased to $10.01 \%$, about 5.6 times more. The growth of women in STEM professions was fueled by younger women. By the latest survey year (2017), the ratio between the two gender groups drops to 1.5:1 (down from 3:1 in 2001). The growth of women in STEM professional occupations fueled by higher education expansion, to a certain degree, offset the position vacancy which could not be filled only by men.

Figure $4.2 \mathrm{~B}$ visualizes the percentage of the population who got a college education in STEM and also had STEM professional positions. Over the past 38 years, women always had a higher percentage of matching between STEM education and occupation compared to men in their age cohort. This trend barely changed even though there was a significant increase in the number of women who were awarded bachelor's degrees in STEM, which suggests that women who completed STEM degrees were more determined to pursue STEM careers. Also, there is no sign to show any discrimination against women in the labor market of STEM professional occupations. Women are treated equally at their early career stage if they have educational opportunities to earn STEM professional qualifications.

\section{Discussion}

Educational expansion in Taiwan was a policy initiative aimed at generating greater educational equality and accessibility. Although educational expansion has been criticized as the cause for over-education and stagnant wage growth in recent years (Green \& Henseke, 2016), this study documents how such policy changed the participation patterns of women in STEM and the subsequent labor market in Taiwan. The expansion of tertiary education created 
opportunities for both men and women with Taiwanese women taking modest advantage of such opportunities to enroll in more STEM programs. Coupled with the decreased enrolment pattern into STEM programs by men in recent years, this Taiwanese case provides a historical perspective revealing how the transformation of education could help reduce gender inequality in STEM (Ramirez \& Wotipka, 2001).

Within the Taiwanese context, the delayed streamlining at the upper secondary school level prevented women from being filtered out of the STEM educational pathway. However, the leaky pipeline phenomenon women face between the upper secondary and tertiary levels was still severe. The possible self-selection or gender stereotyping during their teenage year still constrained girls' interests to explore STEM careers. When Taiwan expanded its tertiary education system, more and more youth had access to university education, but less and less youth showed interest in STEM careers. This tendency did not exclusively happen among women but with men as well. However, compared to older generations, younger women benefited from educational expansion because of greater opportunities to study at four-year universities and complete four-year professional degrees in STEM. They were more likely to obtain the educational qualifications required for the labor market in STEM fields.

These findings fill an important knowledge gap within the scarce literature concerning women in STEM and educational equality within the context of tertiary education expansion in Taiwan. Although much of the literature cited was from US sources, similar dynamics can be observed within the Taiwanese context. An expanded tertiary education system does provide opportunities for women, and for men, to increase their human capital within STEM fields. However, our findings also show that Taiwanese women are still prone to opt out of STEM fields during their upper secondary and tertiary education schooling levels.

These findings have two important policy implications. First, Taiwan's case shows that expanded capacity at the upper secondary level does not guarantee gender equality in STEM tertiary education. Women may still not choose STEM because of gender stereotypes. In this sense, the career exploration programs, which enhance youth's knowledge of each occupation, should be emphasized in the educational system, particularly in secondary schools. Second, tertiary education expansion did improve gender inequality in the labor market by providing women more opportunities to complete professional education in STEM fields. Young women seized the opportunity and completed STEM professional education, as did young men. This opportunity could not have happened if the capacity to access university STEM programs was still limited. However, there is still a clear ceiling effect constraining the growth of women in the STEM educational pipeline as documented in our study. This scenario sends a warning to policymakers that aggressive intervention to improve gender inequality is still needed in the educational system. 


\section{Conclusion}

Using national longitudinal data from 1979 to 2017 that surveyed the educational attainment and occupational choice of women in the labor market, our historical analysis shows that the process of educational expansion could bring many benefits to the underrepresented population group which traditionally used to be excluded from the education system. Using Taiwan as our case study, our findings remind researchers and policymakers that it might be necessary to reevaluate the pros and cons of educational expansion from a holistic perspective. It is not enough to only look at superficial data; rather, it is essential to consider how policy actions, like transforming two-year junior colleges to four-year universities and expanding a nation's education system, have impacted educational participation over the years.

As documented in this Taiwanese case study, diversified educational participation, like having more women receiving professional education in STEM as a result of education expansion, further facilitates the diversity of the labor market. Such dynamics can help develop human capital for science production and keep the momentum of national development in the era of the knowledge economy.

\section{Note}

1 The first author has been part of the Ministry of Education from 2007 to 2018 and engaged in the formation of higher education policy, which helped the authors identify and understand these materials.

\section{References}

Academia Sinica. (2018). Manpower utilization quasi-longitudinal data: 1979-2017 [data file]. Available from Survey Research Data Archive, Academia Sinica.

Astin, H. \& Sax, L. (1996). Developing scientific talent in undergraduate women. In C. Davis, A. Ginorio, C. Hollenhead, B. Lazarus, P. Rayman, \& Associates (Eds.), The equity equation: Fostering the advancement of women in the sciences, mathematics, and engineering (pp. 96-121). Jossey-Bass.

Baker, D. (2011). Forward and backward, horizontal and vertical: Transformation of occupational credentialing in the schooled society. Research in Social Stratification and Mobility, 29, 5-29.

Beede, D., Tiffany, J., \& Langdon, D. (2011). Women in STEM: A gender gap to innovation (Issue Brief No. 04-11). U.S. Department of Commerce. https://eric-ed-gov. libproxy.library.unt.edu/contentdelivery/servlet/ERICServlet?accno=ED523766

Bentley, J. T., \& Adamson, R. (2003). Gender differences in the careers of academic scientists and engineers: A literature review. (Report no. 00-327). www.nsf.gov/sbe/ srs/nsf03322/pdf/nsf03322.pdf

Blickenstaff, J. C. (2005). Women and science careers: Leaky pipeline or gender filter? Gender and Education, 17(4), 369-386.

Breen, R. (2010). Educational expansion and social mobility in the 20th century. Social Forces, 89, 365-388. 
Ceci, S. J., \& Williams, W. M. (2010). Sex differences in math-intensive fields. Current Directions in Psychological Science, 19, 275-279.

Chang, D. F. (2018). Effects of higher education expansion on gender parity: A 65-year trajectory in Taiwan. Higher Education, 76(3), 449-466.

Chang, D. F., \& ChangTzeng, H. C. (2018). Patterns of gender parity in the humanities and STEM programs: The trajectory under the expanded higher education system. Studies in Higher Education, 45(6), 1108-1120.

Cheryan, S., Siy, J. O., Vichayapai, M., Drury, B. J., \& Kim, S. (2011). Do female and male role models who embody STEM stereotypes hinder women's anticipated success in STEM? Social Psychological and Personality Science, 2(6), 656-664.

Corbett, C., \& Hill, C. (2015). Solving the equation: The variables for women's success in engineering and computing. American Association of University Women.

Diekman, A. B., Brown, E., Johnston, A., \& Clark, E. (2010). Seeking congruity between goals and roles: A new look at why women opt out of STEM careers. Psychological Science, 21, 1051-1057.

DiPrete, T. A., \& Buchmann, C. (2013). The rise of women: The growing gender gap in education and what it means for American schools. Russell Sage Foundation.

Eddy, S. L., \& Brownell, S. E. (2016). Beneath the numbers: A review of gender disparities in undergraduate education across science, technology, engineering, and math disciplines. Physical Review Physics Education Research, 12(2), 1-20.

Flashman, J. (2013). A cohort perspective on gender gaps in college attendance and completion. Research in Higher Education, 54(4), 545-570.

Fox, M. F. (2010). Women and men faculty in academic science and engineering: Social-organizational indicators and implications. American Behavioral Scientist, 53(7), 997-1012.

Frome, P. M., Alfeld, C. J., Eccles, J. S., \& Barber, B. L. (2006). Why don't they want a male-dominated job? An investigation of young women who changed their occupational aspirations. Educational Research and Evaluation, 12(4), 359-372.

Fu, Y. C. (2017). Science production in Taiwanese universities, 1980-2011. In J. J. W. Powell, D. P. Baker, \& F. Fernandez (Eds.), The century of science: The global triumph of the research university (pp. 173-203). Emerald.

Geiger, R., \& Feller, I. (1995). The dispersion of academic research in the 1980s. The Journal of Higher Education, 66(3), 336-360.

Green, F., \& Henseke, G. (2016). Should governments of OECD countries worry about graduate underemployment? Oxford Review of Economic Policy, 32(4), 514-537.

Hannum, E., \& Buchmann, C. (2005). Global educational expansion and socio-economic development: An assessment of findings from the social sciences. World Development, 33, 333-354.

Huang, P. M., \& Brainard, S. G. (2001). Identifying determinants of academic selfconfidence among science, math, engineering, and technology students. Fournal of Women and Minorities in Science and Engineering, 7(4), 315-337.

Jacobs, J. A. (1989). Revolving doors: Sex segregation and women's careers. Stanford University Press.

Kang, J., Hense, J., Scheersoi, A., \& Keinonen, T. (2018). Gender study on the relationships between science interest and future career perspectives. International fournal of Science Education, 41(2), 1-22.

Kelly, A. M. (2016). Social cognitive perspective of gender disparities in undergraduate physics. Physical Review Physics Education Research, 12(2), 1-13. 
Kinzie, J. (2007). Women's paths in science: A critical feminist analysis. New Directions for Institutional Research, 133, 81-93.

Konrad, A. M, Ritchie, J. E. Jr., Lieb, P., \& Corrigall, E. (2000). Sex differences and similarities in job attribute preferences: A meta-analysis. Psychological Bulletin, 126(4), 593-641.

Lee, J. A. (2008). Gender equity issues in technology education: A qualitative approach to uncovering barriers [Doctoral dissertation, North Carolina State University]. ProQuest Dissertations \& Theses Global]. https://libproxy.library.unt.edu/login?url=https://www-p roquest-com.libproxy.library.unt.edu/docview/304536802? accountid=7113

Lee, J. K., Alston, A. T., \& Kahn, K. B. (2015). Identity threat in the classroom: Review of women's motivational experiences in the sciences. Translational Issues in Psychological Science, 1(4), 321

Mann, A., \& DiPrete, T. A. (2013). Trends in gender segregation in the choice of science and engineering majors. Social Science Research, 42, 1519-1541.

Marginson, S. (2016). The worldwide trend to high participation higher education: Dynamics of social stratification in inclusive systems. Higher Education, 72(4), 413-434.

Ministry of Education. (2019a). Higher education statistics. Retrieved from: https:// eng.stat.gov.tw/public/data/dgbas03/bs2/yearbook_eng/y015.pdf

Ministry of Education. (2019b). Education statistical indicators [Data sets]. https:// english.moe.gov.tw/cp-86-18943-e698b-1.html

Okamoto, D., \& England, P. (1999). Is there a supply side to occupational sex segregation? Sociological Perspectives, 42, 557-582.

Penner, A. (2015). Gender inequality in science. Science, 347(6219), 234-235.

Ramirez, F. O., \& Wotipka, C. M. (2001). Slowly but surely? The global expansion of women's participation in science and engineering fields of study, 1972-92. Sociology of Education, 74(3), 231-251.

Riegle-Crumb, C., Moore, C., \& Ramos-Wada, A. (2011). Who wants to have a career in science or math? Exploring adolescents' future aspirations by gender and race/ ethnicity. Science Education, 95(3), 458-476.

Saucerman, J., \& Vasquez, K. (2014). Psychological barriers to STEM participation for women over the course of development. Adultspan fournal, 13(1), 46-64.

Seaton, G. A. (2011). Belonging uncertainty and psychological capital: An investigation of antecedents of the leaky pipeline in STEM [Master's thesis, Purdue University].

Severiens, S., \& ten Dam, G. (2012). Leaving college: A gender comparison in male and female-dominated programs. Research in Higher Education, 53, 453-470.

Seymour, E., \& Hewitt, N. M. (1997). Talking about leaving: Why undergraduates leave the sciences. Westview Press.

Shapiro, C. A., \& Sax, L. J. (2011). Major selection and persistence for women in STEM. New Directions for Institutional Research, 2011 (152), 5-18.

Shavit, Y., Arum, R., Gamoran, A., \& Menahem, G. (2007). Stratification in higher education: A comparative study. Stanford University Press.

Smith, E. (2011). Women into science and engineering? Gendered participation in higher education STEM subjects. British Educational Research Fournal, 37(6), 993-1014.

Sonnert, G., Fox, M. F., \& Adkins, M. (2007). Undergraduate women in science and engineering: Effects of faculty, fields and institutions over time. Social Science Quarterly, 88(5), 1333-1356.

Trow, M. (1973). Problems in the transition from elite to mass higher education. http://files.eric.ed.gov/fulltext/ED091983.pdf 
U.S. Department of Commerce \& National Economic Council. (2012). The competitiveness and innovative capacity of the United States. https://www.commerce.gov/ sites/default/files/migrated/reports/thecompetitivenessandinnovativecapacityoftheu nitedstates.pdf

van den Hurk, A., Meelissen, M., \& van Langen, A. (2019). Interventions in education to prevent STEM pipeline leakage. International Fournal of Science Education, 41(2), 150-164

van Staden, A., Ahmed, N., Getachew, Y., Gledhill, I. M. A., Kanjere, M., KhuluseMakhanya, S., \& Das, S. (2019). 'Gender shouldn't matter because we are all scientists here': A narration of the panel discussion at the 2nd International Women in Science Without Borders conference. South African Fournal of Science, 115(3/4), 33-36.

Wang, M. T., \& Degol, J. (2013). Motivational pathways to STEM career choices: Using expectancy-value perspective to understand individual and gender differences in STEM fields. Developmental Review, 33(4), 304-340.

Xie, Y., \& Shauman, K. A. (2003). Women in science: Career processes and outcome. Harvard University Press.

$\mathrm{Xu}, \mathrm{Y}$. (2015). Focusing on women in STEM: A longitudinal examination of genderbased earning gap of college graduates. The Journal of Higher Education, 86(4), 489-523. 